\title{
The CMA songstress of Saskatchewan
}

$\mathrm{F}$ amily physician in Saskatoon, Saskatchewan ... mother of 6 children ... associate professor of obstetrics ... advisor and advocate for various professional organizations ... registered federal lobbyist ... until she recently suffered a shoulder injury, a competitive swimmer ... a referee who'll be on the deck at the Canada Games pool in Charlottetown, Prince Edward Island later this month ... volunteer and activist for various medical initiatives, including programs for breast and cervical cancer ... former grain farmer ... choir singer.

Renaissance woman?

Whirlwind?

The most organized person in Saskatchewan?

"No," says Dr. Anne Doig, the new president of the Canadian Medical Association. "It's organized chaos most of the time."

"You focus on the thing that is of immediate importance. A lot of things get done in your head and get done when they get done. I don't know how I do it. This is like the question that I used to get asked when the kids were little. People would see me traipsing around with 6 kids in tow and they'd say 'Oh my God, 6 kids: how do you do it?' The only answer I could come up with was: one at a time. I guess that's how I get other things done too. I focus on what I'm doing at the time and the other things are bouncing around in the back of my brain and when they have to come to the forefront, they come, one at a time.'

"Maybe it's latent ADHD [attention-deficit hyperactivity disorder] or something," Doig quips.

A few minutes with Doig and it's clear that the Canadian Medical Association's new president is nothing if not a wit. The lay reader at the Holy Spirit Roman Catholic Church wryly notes, for example, that she has a periodic need to foray to the All Saints Anglican Church, where she is a member of the senior choir, to belt out a few classic choral pieces, rather than the "Jesus is my boyfriend music," to which thoroughly modern Catholic priests now often dance around the recessional.

The latter is a phrase rarely heard in the current era in which there is widespread perception that physicians speak first with the voice of financial selfinterest, particularly with respect to the relentless debate over medicare.

But Doig argues that is a misperception caused by a media obsessed with "2-minute sound bites," prone to casting the debate over sustainability of the system as a matter of compensation for doctors, rather than one of timely access to medical care. "The question is not how we're going to pay for it. The fact is we are paying for it. What the focus needs to be is care, not medicare. You know, it's not about medicare. Medicare is. Medicare is a reality. Medicare exists. What it's about is trying to make that system functional so that we can go from being 30 out of 30 in value for the dollar spent in health spending."

In that context, Doig argues that solutions must come from physicians, as they are the ones most familiar with the systemic changes that are needed to ensure long-term sustainability and they are the only ones who can serve as the authoritative voice for the needs of patients. To that end, Doig says, her first priority as president will be to canvas Canada's practicing doctors "to find out what the folks out there are dealing with and what good ideas many of them have for fix-

New CMA president Dr. Anne Doig says she's "not known for being silent."
What is equally apparent after just a few minutes with Doig is that she is also a woman with a very firm moral compass. Whether talking about her priorities as president, wait times, physician shortages or the debate about public versus private financing of health care, phrases like "the right thing to do," "our responsibility," and the "ethical principle of putting patients first" creep constantly into her conversation. ing what's wrong."

She calls it "ludicrous" that bottlenecks like the chronic shortage of physicians (and therein, the lack of a national health human resources strategy, CMAJ 2009;180[3]:284 and CMAJ 2006;174[13]:1827-8), or the lack of adequate long-term care programs, have not been resolved. "Why do we not have enough resources both to support people that are providing 
care at home with semi-skilled caregivers and those that are being looked after in more institutionalized settings? Why isn't there enough there? If there were enough resources in that area, perhaps there would be less pressure on our emergency rooms. There would be a way of using our acute-care beds more efficiently because we wouldn't have them filled up with people who can't be cared for in the community and don't have anywhere else to go."

Doctors must be given more input into administrative and policy decisions if the system is to remain functional and avoid such miscues as the ones in the late 1980s and 1990s that led to a severe reduction in the number of spots available at medical schools.

"What we do want is people to listen to what the docs are saying because, dammit, this is our own business and we know our business and we're a little tired of other people thinking they know our business better than we know our business. Our business is patient care."

In the long run, that may mean more private health care, Doig says. "Let's be realistic about it. If there's a better way of doing things, so that the majority will all benefit, then people are going to look for a better way of doing things, and whether that means sourcing certain suppliers, or sourcing certain equipment, or paying for things somewhat differently, perhaps those are answers we need to look to. But what I'm trying to say to you is that's not the main focus of the answer."

Yet with the past 2 CMA presidents having been private clinic owner-operators and consequent widespread public perception that the association has become a voice for the development of a parallel private health care system, Doig is also very careful to stress that most of Canada's physicians are not trying to undermine medicare.

While the vast majority of physicians are private practitioners, "we practise in a publicly funded system," says Doig, who received her MD from the University of Saskatchewan in 1976. "None of us wants to cut the nose off our own faces. We're not here to destroy public funding. We're here to try and make the care we're giving patients better."

From that perspective, Doig might well be labeled a "pragmatist" in the endless public-private debate. But she's quick to eschew the tag. "I don't like labels, so I'm not going to agree with that statement. I do not like labels of any sort.'

The daughter of Dr. J. Noel Doig, who was active in the 1962 medicare crisis in Saskatchewan, during which doctors struck to protest universal health care, Doig and husband Robert Cowan, a mechanical engineer, have 5 sons and a daughter. The couple owned and operated a grain farm near Rosetown from 1994 to 2007. — Wayne Kondro, CMAJ

DOI:10.1503/cmaj.091356 